\title{
SINGLE-CRYSTAL SILICON CONTINUOUS MEMBRANE DEFORMABLE MIRROR WITH PZT UNIMORPH MICROACTUATOR ARRAYS
}

\author{
Yoshikazu Hishinuma ${ }^{\dagger}$, and Eui-Hyeok(EH) Yang \\ Jet Propulsion Laboratory, California Institute of Technology \\ 4800 Oak Grove Dr., Pasadena, California 91109 \\ ${ }^{\dagger}$ yoshikazu.hishinuma@jpl.nasa.gov
}

\begin{abstract}
For the first time, this paper reports on fabrication, assembly and testing of piezoelectric unimorph-based deformable mirrors (DMs) with continuous single-crystal silicon deformable membranes. A PZT unimorph actuator of $2.5 \mathrm{~mm}$ in diameter with optimized PZT/Si thickness and design showed a deflection of $5 \mu \mathrm{m}$ at $50 \mathrm{~V}$. DMs consisting of $10 \mu \mathrm{m}$ thick single-crystal silicon membranes supported by $4 \times 4$ actuator arrays were fabricated and optically characterized. An assembled DM showed a stroke of $2.5 \mu \mathrm{m}$ at $50 \mathrm{~V}$ with a resonant frequency of $42 \mathrm{kHz}$ and influence function of approximately $25 \%$.
\end{abstract}

\section{INTRODUCTION}

The future deployment of ultra-large, light weight space telescopes is being envisioned by NASA. However, deploying conventional, large area, rigid primary mirrors in space is prohibitively expensive. Therefore, it is planned to construct telescopes with either segmented apertures or with relatively flexible monolithic primary mirrors whose large surface errors can be corrected using subsequent active or adaptive wavefront control [1]. These concepts could potentially involve wavefront errors greater than several wavelengths. Thus, the key optical component needed for effective wavefront compensation is an optical quality, large-stroke, continuous-membrane DM with high actuator density over large areas (Fig. 1). DMs with mirror surface quality of $<10 \mathrm{~nm}$ can be fabricated using the membrane transfer technique demonstrated by our group [2]. Other desirable characteristics of DMs include mirror actuation of $>2 \mu \mathrm{m}$ at $<50 \mathrm{~V}$ $(<1 \mu \mathrm{W}$ per pixel), with a bandwidth of $>1 \mathrm{kHz}$, and influence function of $<30 \%$. Micromachined DMs have been previously reported (Table 1), however they needed high-voltage operation due to electrostatic operation (100-700V) [3-7], small stroke
$(<2 \mu \mathrm{m})[3-5,7]$, marginal surface quality [3,5], or high influence function (crosstalk) $[4,5]$. In this paper, we present a singlecrystal silicon continuous membrane DM, incorporated for the first time with underlying piezoelectric unimorph actuators.

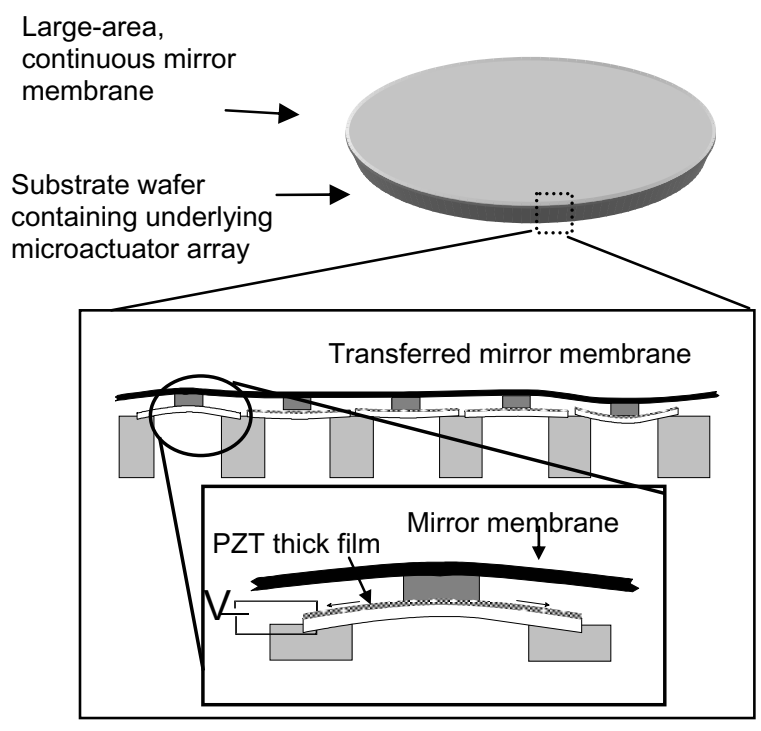

Figure 1. Large-area continuous membrane deformable mirror (DM) concept. For minimizing the effect of print-through, the silicon mirror membrane is required to be thicker than $10 \mu \mathrm{m}$ thick. The mirror membrane is backed by an array of piezoelectric unimorph microactuators. The advantage of this approach is that the small strains obtainable from a piezoelectric material at modest voltages are translated into relatively large displacements.

\begin{tabular}{|c|c|c|c|c|c|c|}
\hline & Requirements & $\begin{array}{c}\text { Boston } \\
\text { University }^{3}\end{array}$ & $\begin{array}{c}\text { Stanford } \\
\text { University }\end{array}$ & $\begin{array}{l}\text { Grenoble, } \\
\text { France }^{6}\end{array}$ & Bell Lab ${ }^{7}$ & JPL \\
\hline Stroke (1 actuator) & $>2 \mu \mathrm{m}$ & $2 \mu \mathrm{m}$ & $1 \mu \mathrm{m}$ & $2 \mu \mathrm{m}$ & $2 \mu \mathrm{m}$ & $2.5 \mu \mathrm{m}$ \\
\hline Bandwidth & $>1 \mathrm{kHz}$ & $7 \mathrm{kHz}$ & $2 \mathrm{kHz}$ & $1 \mathrm{kHz}$ & $4 \mathrm{kHz}$ & $40 \mathrm{kHz}$ \\
\hline $\begin{array}{l}\text { Actuation } \\
\text { voltage }\end{array}$ & Low & $240 \mathrm{~V}$ & $200 \mathrm{~V}$ & $150 \mathrm{~V}$ & $100 \mathrm{~V}$ & $50 \mathrm{~V}$ \\
\hline $\begin{array}{l}\text { Actuation } \\
\text { mechanism }\end{array}$ & -- & Electrostatic & Electrostatic & Electrostatic & Electrostatic & $\begin{array}{l}\text { Piezo- } \\
\text { unimorph }\end{array}$ \\
\hline Surface quality & $<25 \mathrm{~nm}$ & $30 \mathrm{~nm}$ RMS & - & $180 \mathrm{~nm}$ & - & $30 \mathrm{~nm}$ RMS \\
\hline $\begin{array}{c}\text { Mirror } \\
\text { membrane }\end{array}$ & -- & $2 \mu \mathrm{m}$ poly-Si & $10 \mu \mathrm{m} \mathrm{Si}$ & $1 \sim 5 \mu \mathrm{m} \mathrm{SC} \mathrm{Si}$ & $1 \sim 3 \mu \mathrm{m} \mathrm{SC} \mathrm{Si}$ & $10 \mu \mathrm{m} \mathrm{SC} \mathrm{Si}$ \\
\hline
\end{tabular}

Table 1. Comparison table of existing MEMS DM specifications 


\section{PZT UNIMORPH ACTUATOR}

We have modeled, fabricated and characterized a series of PZT unimorph membrane actuators with various membrane designs in order to optimize the DM actuator geometry. Fig. 2 contains (a) a photograph of fabricated actuators of various types and (b) a schematic illustration of the actuator structure. Electrode designs which have been tested include: plain circles, concentric rings, spirals, and segmented electrodes.

(a)

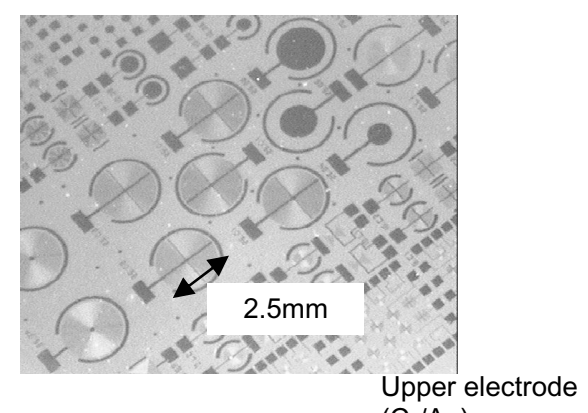

(b)

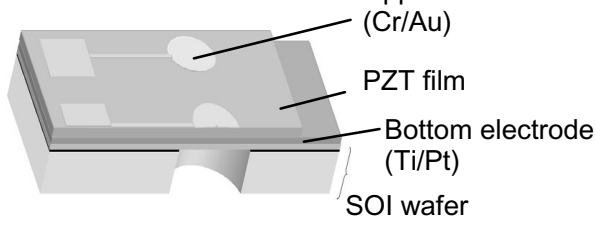

Figure 2. (a)A photograph of PZT actuator array (b)Schematic diagram showing the structure of a PZT unimorph actuator

The actuation principle is as follows: An electric field applied perpendicular to the piezoelectric layer plane induces contraction in the lateral direction, producing a large out-of-plane deflection because of its unimorph geometry. Compared to piezoelectric stacks that are widely used in commercial DMs, this actuation mechanism requires far less voltage and power to produce same amount of deflection. We have discovered that there are two regimes of unimorph membrane actuators depending on the PZT film / silicon membrane thickness ratio. For thin silicon membranes (less than or equal to the PZT layer thickness), concentric rings and spiral electrode designs produced more deflection than full circle electrodes, implying that the stress in the electrode film reduces the amount of deflection significantly. For actuators with thick silicon membranes (greater than twice the PZT thickness), full circle electrodes produced more deflection than the other electrode designs. Since actuators with thick Si membranes showed more promise for DM applications because of the higher deflection and ease of handling during fabrication, we focused our efforts in optimizing the full circle actuator design for thick $\mathrm{Si}$ membranes.

In order to optimize the geometry of the unimorph actuator structure, a mathematical model was developed using an energy minimization method [8]. In this model, the total energy of the unimorph membrane under deflection is calculated using a deflection profile predicted using thin plate deflection theory. Then the total energy, which is the sum of the elastic energy due to the bending of the membrane, the potential energy stored by the film stresses, and the work done by the piezoelectric moment, is minimized with respect to the deflection profile using a Lagrange multiplier method. Fig. 3 shows a WYKO interferometer image of the deflection of the unimorph actuator. The measured thickness dependence of membrane deflection shows excellent agreement with our model (Fig. 4). Fig. 5 shows the deflection dependence versus the size of the electrodes relative to the membranes. The measured deflection for an optimized actuator is $5.4 \mu \mathrm{m}$ at $50 \mathrm{~V}$ (for an actuator with $2.5 \mathrm{~mm}$ diameter, $\mathrm{PZT} / \mathrm{Si}=2 \mu \mathrm{m} / 15 \mu \mathrm{m}$ thick, $60 \%$ electrode diameter).
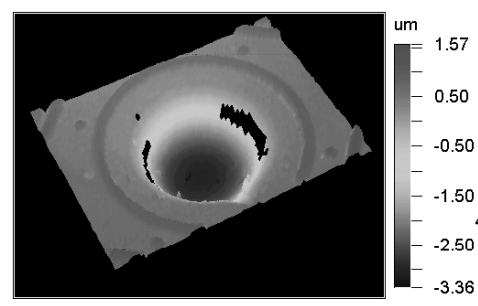

Applied voltage: $50 \mathrm{~V}$

Figure 3. WYKO interferometer image of a PZT unimorph actuator under deflection. The thicknesses of PZT/Si layers are $2 \mu \mathrm{m} / 15 \mu \mathrm{m}$.

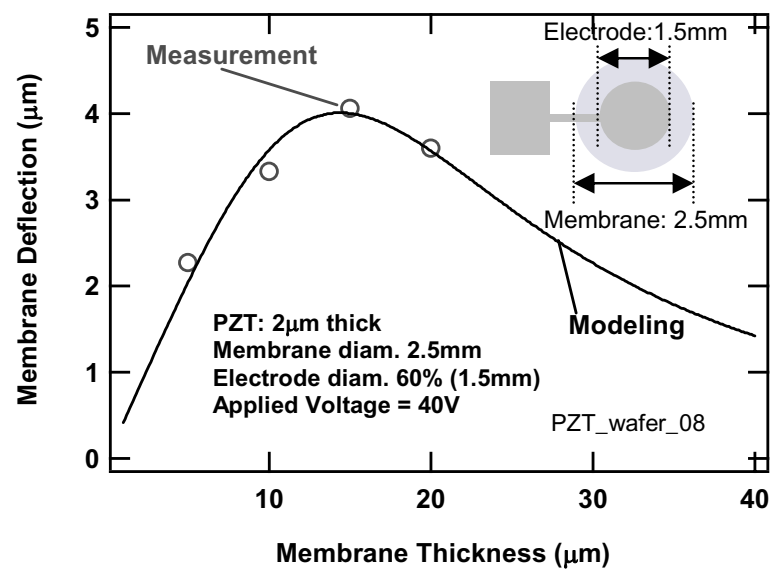

Figure 4. Dependence of deflection on silicon membrane thickness. For membranes $2.5 \mathrm{~mm}$ in diameter, the optimized Si/PZT thickness ratio is approximately $6 . \quad$ The data points represent an average of 10 separate measurements on 2 different pixels within a typical array.

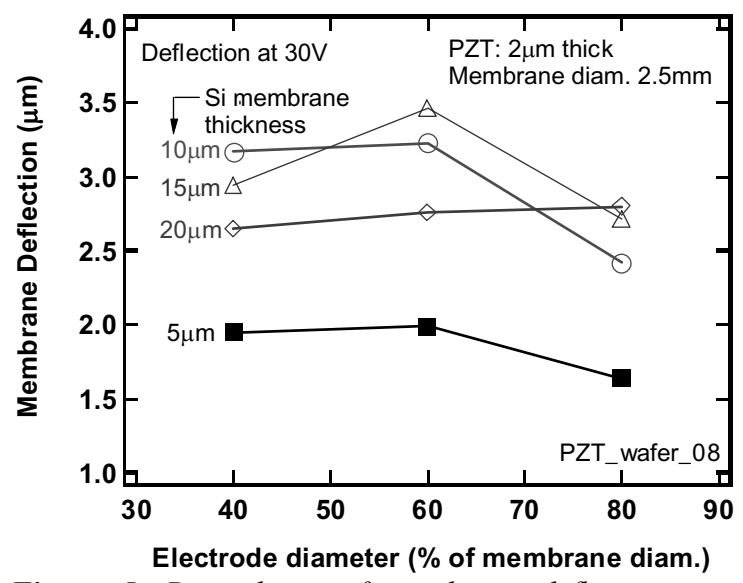

Figure 5. Dependence of membrane deflection on electrode diameter. Optimum electrode diameter is approximately $60 \%$ of the membrane diameter. 


\section{DEFORMABLE MIRROR}

DMs consisting of $10 \mu \mathrm{m}$ thick single-crystal silicon membranes supported by $4 \times 4$ actuator arrays were fabricated and optically characterized. Fig. 6 contains (a) a schematic diagram of the DM structure and (b) a photograph of DMs and the microfabricated arrays of actuators (the upper mirror membrane is intentionally removed). The $\mathrm{Si}$ mirror membrane made from another SOI wafer was bonded onto the actuator wafer via indium posts at the centers of each actuator (Fig. 7).

(a)

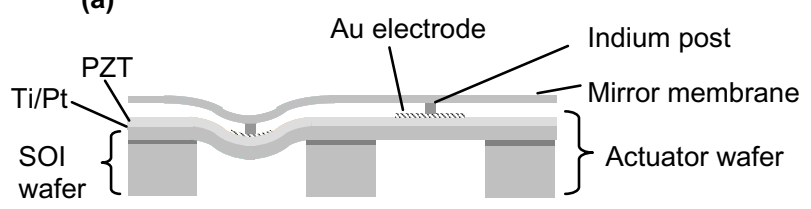

(b)

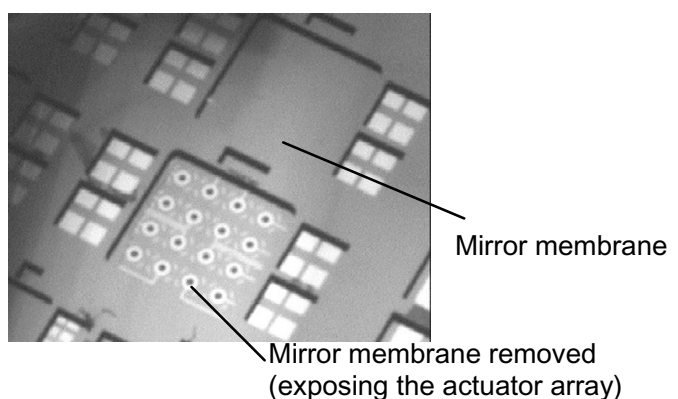

Figure 6. (a) Cross-sectional schematic of the deformable mirror (b) Photograph of microfabricated deformable mirrors with $4 \times 4$ actuator arrays
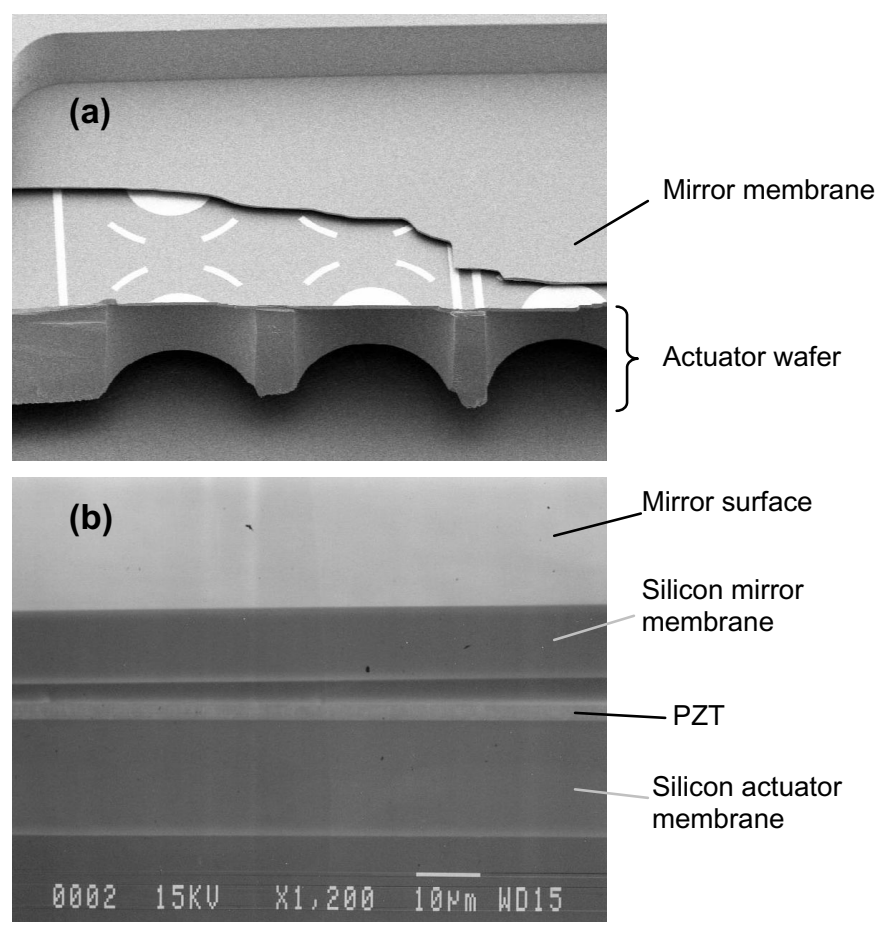

Figure 7. SEM micrographs of the assembled deformable mirror. (a) DM with mirror membrane partially removed. (b) Cross section of the DM: the mirror membrane is $10 \mu \mathrm{m}$ thick to provide the necessary optical quality for the DM.
The surface profile of an actuated deformable mirror using one underlying actuator is shown in Fig. 8. The measured influence function is $25 \%$. Fig. 9 presents the measured deflection $v s$. the applied voltage for an actuator and a DM actuated using a single actuator. The DM shows stroke of $2.5 \mu \mathrm{m}$ at $50 \mathrm{~V}$. The stroke of the mirror membrane is approximately $40 \%$ less than that of the actuator alone. This stroke reduction can be adjusted by changing the mechanical compliance (e. g. optimizing the PZT/ actuator membrane/ mirror membrane thickness ratio). Frequency responses of the unimorph actuator and with the mounted mirror membrane were obtained using a laser-doppler vibrometer (Fig. 10). The measured resonance frequency of $42 \mathrm{kHz}$ far exceeds the bandwidth requirement for most DMs.

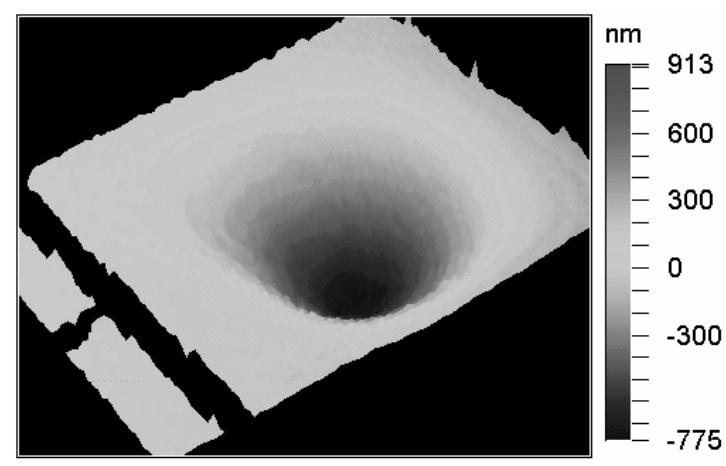

Figure 8. Deflection of a deformable mirror with one actuator activated. From this profile, the influence function (crosstalk between pixels) is approximately $25 \%$.

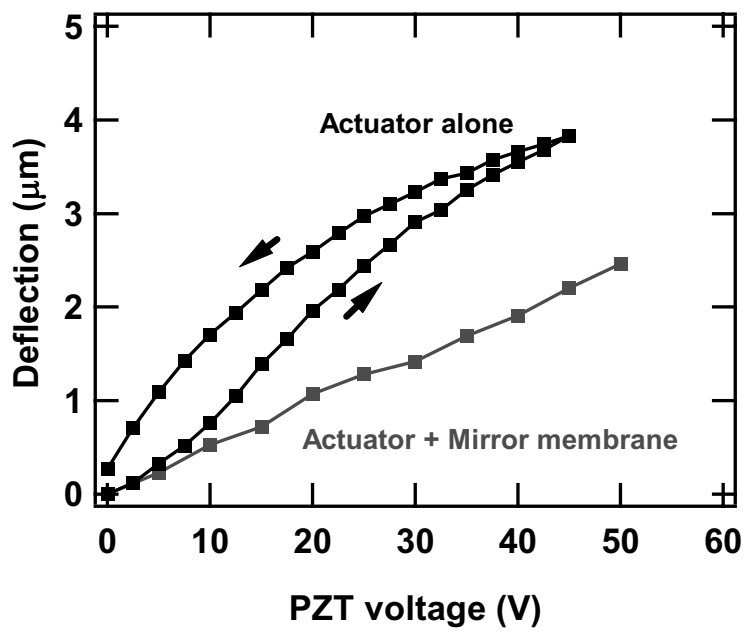

Figure 9. Relative deflection vs. applied voltage for a $2.5 \mathrm{~mm}$ diameter actuator alone and with a mounted mirror membrane. 

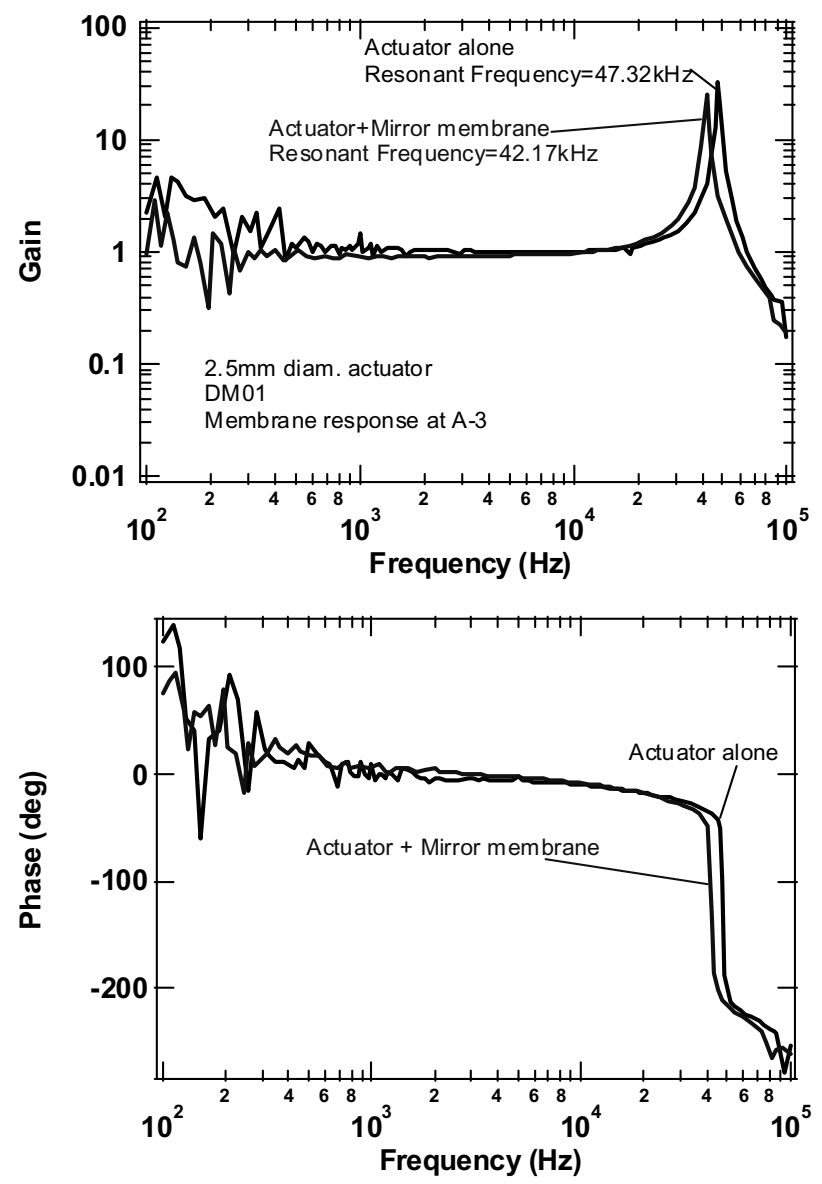

Figure 10. Measured frequency response of the piezoelectric unimorph actuator alone and with a mounted mirror membrane. These plots demonstrate that the DM is capable of high bandwidth operation. They also indicate the high-stiffness of the actuator membrane, which is important for high optical quality mirrors.

\section{CONCLUSIONS}

In summary we have successfully demonstrated the proof-ofconcept for a DM composed of a continuous single-crystal silicon membrane supported by piezoelectric unimorph actuator arrays. Piezoelectric unimorph actuators designed with optimized PZT/Si thicknesses can produce large strokes (as high as $5 \mu \mathrm{m}$ ) at low voltage $(50 \mathrm{~V})$. DMs consisting of $10 \mu \mathrm{m}$ thick single-crystal silicon membranes supported by $4 \times 4$ actuator arrays were fabricated and characterized optically. Improvements in the fabrication process for better optical quality mirror membranes and optimization of the DMs for larger strokes are underway. Additional optical characterization of fabricated DMs will also be performed.

\section{ACKNOWLEDGEMENTS}

The authors would like to thank Dr. Jian-Gong Cheng and Prof. Susan Trolier-McKinstry of Pennsylvania State University for providing PZT depositions on wafers. We would like to acknowledge Dr. Thomas George for his valuable comments throughout this research project. The research described in this paper was carried out at the Jet Propulsion Laboratory, California Institute of Technology, under a contract with the National Aeronautics and Space Administration. Travel support has been generously provided by the Transducers Research Foundation and by the DARPA MEMS and DARPA BioFlips programs.

\section{REFERENCES}

1. R. Dekany, et al., "Advanced Segmented Silicon Space Telescopes (ASSiST)," SPIE International Symp. On Astronomical Telescopes and Instrumentation, Adaptive Optical System Technologies II, 8/22-28/02, Waikoloa, Hawaii (2002).

2. E. H. Yang and D. V. Wiberg "A wafer-scale membrane transfer process for the fabrication of optical quality, large continuous membranes," IEEE/ASME Journal of Microelectromechanical Systems, 12(6), 804 (2003).

3. T. Bifano et al., "Continuous-Membrane SuraceMicromachined Silicon Deformable Mirror", Optical Engineering, 36(5), 1354, (1997); T. Bifano et al., "Micromachined Deformable Mirrors for Adaptive Optics", SPIE Conf. on High-Resolution Wavefront Control: Methods, Devices, and Applications IV, Seattle, WA, 7/8-9/2002, SPIE Int. Soc. Opt. Eng.(2002), pp.1013.

4. J. Mansell et. al., "Silicon Deformable Mirrors and CMOSbased Wavefront Sensors," SPIE Internatinal Conference, HighResolution Wavefront Control, San Diego, CA, 8/1-2/2000, SPIE Int. Soc. Opt. Eng. (2000), pp.15-25.

5. G. Vdovin, "Optimization-based Operation of Micromachined Deformable Mirrors," SPIE Conf. on Adaptive Optical System Technology, Kona, Hawaii, SPIE Int. Soc. Opt. Eng. (1998), pp.902-909.

6. C. Divoux, et al., "A Novel Electrostatic Actuator for Micro Deformable Mirrors: Fabrication and Test", International Conference on Solid State Sensors, Actuators, and Microsystems, Boston, MA 6/8-12/03, IEEE(2003), pp.488-491.

7. P. Kurczynski, et al., "Electrostatically actuated membrane mirrors for adaptive optics", SPIE Conf. on MOEMS and Miniaturized Systems III, San Jose, CA (2003), pp. 305-313.

8. P. Muralt, et al., "Piezoelectric actuation of PZT thin-film diaphragms at static and resonant conditions", Sensors and Actuators A, 53, 398 (1996). 